\title{
Cultura Cultura
}

Revista de Historia Terorid das deaias - Revista de História e Teoria das Ideias

Vol. 22 | 2006

Ideias políticas

\section{Mas, afinal, o que é uma biblioteca?}

Como se de uma aula de História Moderna se tratasse

\section{António Camões Gouveia}

\section{(2) OpenEdition}

Journals

\section{Edição electrónica}

URL: http://journals.openedition.org/cultura/2138

DOI: $10.4000 /$ cultura. 2138

ISSN: 2183-2021

Editora

Centro de História da Cultura

\section{Edição impressa}

Data de publição: 1 Janeiro 2006

Paginação: 21-28

ISBN: 0870-4546

ISSN: 0870-4546

\section{Refêrencia eletrónica}

António Camões Gouveia, « Mas, afinal, o que é uma biblioteca? », Cultura [Online], Vol. 22 | 2006,

posto online no dia 23 junho 2015, consultado a 19 abril 2019. URL : http://journals.openedition.org/ cultura/2138; DOI : 10.4000/cultura.2138

Este documento foi criado de forma automática no dia 19 Abril 2019.

(c) CHAM - Centro de Humanidades / Centre for the Humanities 


\title{
Mas, afinal, o que é uma biblioteca?
}

Como se de uma aula de História Moderna se tratasse

\author{
António Camões Gouveia
}

\section{Primeiro registo - o histórico. 0 que é uma Biblioteca I. Apontamentos. (para aulas e futuras investigações)}

A importância da leitura, e das suas aprendizagens, e do livro, na sua construção enquanto objecto de saber. o livro como "bem cultural", depois, temporalmente explorado como património, ou por um conjunto de leitores credenciados, normalmente intelectualizados, a quem poderemos chamar "produtores de ideias", ou por um grupo local, "eruditos", ou nacional, "políticos" (?), constroem o livro como objecto de valor acumulado, fruto da técnica e transporte expresso de pensamento.

Toda esta constatação é mais flagrante e perceptível, uma vez abandonado, ou pelo menos acantonado, o livro do copista, raro, precioso e muito religioso e imposto o objecto impresso, percorrendo espaços de línguas diferentes, tornando o autor existente mas não conhecível.

Aperfeiçoadas as técnicas, por novas profissões da cidade, os exímios técnicos e artistas, detentores de saberes próprios, impressores-tipógrafos e gravadores, multiplicado o livro, embaratecido na produção e consequente aquisição, desenvolve-se um comércio pouco suspeitado até aí, o mercado livreiro, possivelmente uma das primeiras áreas de comércio cultural desenvolvidas na história da Europa. Porque tudo isto é Europa, uma Europa muito do centro, articulado com um eixo renano próspero e, sobretudo, necessitando de afirmação de autonomia.

É importante voltar aos conteúdos. O crescimento dos livros em circulação, e consequente número possível de leitores, obriga a referir que as temáticas religosas se mantêm e predominam. A ideia do livro "muito religioso", escrito por gente da religião para gente da religião e dentro dos cânones da religião, é agora, este agora refere o tempo explosivo da primeira modernidade, o tempo do Renascimento/Reformas, uma necessidade de diferença. 
No livro se passam a condensar os saberes críticos que ultrapassam a "relectio" escolástica, numa afirmação do acesso aos textos originais, "nascimento", libertos de comentários e glosas interlineares e marginais, descomplexificados dos saberes de interpretações de vário nível, todas elas proporcionadoras de envolventes cerzimentos de "ideias feitas", como que filtros de acesso ao original. Aceder a esses originais, "renascer", implicou, pois que o livro religioso mantivesse a primazia de impressão, divulgação, venda e leitores.

Mas esse religioso era construído num racional exercício de "livre-exame". Fixam-se textos, comparando versões, recusando intromissões de escribas anteriores, apontando novas possibilidades de leitura, novas e diferentes linhas e páginas restauradas. Procura fixar-se o complexo conjunto de livros que é a Bíblia (neste sentido a Bíblia não é um exemplo acabado de Biblioteca?). Intrometem-se autores, mais ou menos teólogos, "humanistas", na árdua tarefa de descortinar historicidade nos textos de "mão divina". Vão mais longe. Tentam rectificar as traduções, o que ali se diz a alguns em latim, pode ser dito, e por vezes de forma mais correcta, a muitos, em linguagem de todos os dias. Revolução que se soma à da imprensa, ou fusão de ideias e práticas de cultura?

Paralelo aos livros do religioso crescem os de outros poderes, do Príncipe e sobre o Príncipe, daqueles que executam ou têm formas próprias de executar, com leis (juristas, "burocratas modernos", ...), com aritmética e álgebra (mercadores, navegadores, ...), com novos saberes (cartógrafos, astrónomos, botânicos, anatomistas, ...) ou simplesmente dos que "civilizam", as mais das vezes "cristãmente" (missionários, pregadores, ...), e querem deixar correr os seus sentimentos e gosto de adorar a Deus, ver e criticar os homens, suspi rar pelo amor das mulheres e observar o mundo (poetas, viajantes, ... mas, também músicos, gravadores, que indelevelmente tão associados estão ao livro!, pintores, ... gente do nascente teatro).

Livro, livros, muito mais livros; uma circulação que cria novas profissões, um mercado, um primeiro mercado de cultura, uma diferença que tem por base a crítica e que resulta em multiplicação.

Muitos livros. Livros que crescem longe dos "scriptorium", que se coleccionam, que se arrumam, que, fisicamente, conduzem o saber do autor, condensado em escrita impressa até à Biblioteca (a ideia e este percurso estão desde logo expressos no título da feliz síntese de Bouza Álvarez). A Biblioteca como acumulação/colecção não é novidade, tem até o mérito de possibilitar um excurso a propósito das Bibliotecas da Antiguidade, sobretodas, Alexandria. Mas a Biblioteca pode ser "não física", pode ser uma colecção de saberes e opiniões que estão contidos em livros que se referem, citam ou "arrumam" em catálogo (aqui nunca será de mais referir a magistral e majestática Bihliotheca Lusitana (1741-1759) de Diogo Barbosa Machado e remeter para o exemplar trabalho sobre a "Biblioteca" de Jorge Cardoso estudada por Maria de Lurdes Correia Fernandes).

Tudo isto são deias de síntese, com muitas problemáticas a desenvolver e chamadas de atenção aos limites da interpretação.

Primeira conclusão possível: uma Biblioteca é um conjunto de livros. 


\section{Primeiro registo - o histórico-documental. 0 que é uma Biblioteca 2. Fichas de excertos de antologia. (passagens a comentar ou a citar)}

[uma biblioteca de poetas lusitanos]

Diogo Bernardes (1530-1605). O Lima (1596).

Carta XXX. A Gaspar de Sousa sobrinho do mesmo Dom Cristovão de Moura.

“(...).

Naõ morri nunca por juntar tisouro,

Nunca pretendi mais que defenderme

Da graã fome, e do frio de que mouro,

Se vejo, como espero responderme

De maneira, que possa a mais quieto

Co as Musas em ocio recolherme:

De juntar os bons versos vos prometto

Dos Poetas insignes Lusitanos

Aprovados por Febo, em seu decreto."

(ed. Marques Braga. Lisboa: Sá da Costa, 1946, vol.II, p.323)

[as matérias/"géneros" dos livros de uma biblioteca]

Francisco Rodrigues Lobo (1580-1622). Corte na Aldeia (1619). Diálogo I

“(...).

Cada um diga a sua opinião nos livros que mais lhe contentam e das razões que tem para os aprovar; e, deste modo, ou afeiçoados ou convencidos, saberemos os que são de maior gosto e utilidade. (...).

E, não tratando dos Livros Divinos, nem dos necessários, dos de recreação nos podeis dizer quais e por que razões vos contentam. (...).

Sou particularmente afeiçoado a livros de história verdadeira, e, mais que às outras, às do Reino em que vivo e da terra onde nasci. ( ...).

E havendo um homem de ler o que não é, ou o que sai tão caldeado e tão batido da forja dos autores que mudado traz o metal, a cor e a natureza, estou melhor com os livros de cavalarias e histórias fingidas, que, se não são verdadeiros, não os vendem por esses; e são tão bem inventados que levam após si os olhos e os desejos dos que os lêem. (...).

Poesia levantada sobre os bons conceitos e versos. (...).

Como exceptuastes Livros Divinos, nesse número devem estar os dos poetas que mereceram este nome. (...).

O melhor modo de escrever são os diálogos escritos em prosa, com figuras introduzidas que disputem e tratem matérias proveitosas, políticas, engraçadas e cheias de galantaria, sendo a primeira figura da obra o autor dela; e esse que vá guiando e introduzindo as mais, que sejam apropriadas àquelas matérias de que hão-de tratar entre si.(...).

Porque a mim me parece que à escritura se deve o melhor lugar, e que antes merecia a prática por se parecer com ela."

(ed. José Adriano de Carvalho. Lisboa: Editorial Presença, 1992, p.60, 61, 64, 65, 66).

[as grandes secções de urna Biblioteca Lusitana]

Francisco Manuel de Melo (1608-1666). Cartas Familiares (1664). Ao Dr. Manuel Temido da Fonseca, Vigairo Geral do Arcebispado de Lisboa (1650).

“(...). 
Levado deste pensamento, procurei por mimesmo, e despois persuadi a alguas pessoas doutas, publicássemos no Biblioteca Lusitana dos Autores Modernos, novamente estimulado da falta que padecemos nesta parte. (...)

Nas ciências divinas e humanas (...). A Filosofia (...). Na Retórica e letras humanas (...). A Latinidade (...). Nas Matemáticas (...). Na Medicina (...). Logo passando aos Políticos (...). Não terá a História dos portugueses agora aquela antiga queixa de que se aplicavam menos a escrevê-la que a merecê-la. (...). As Apologias (...). A Teologia (...). O Moral (...). Não menos a Música (...). As ciências políticas (...). Nos Cânones sagrados (...)."

(ed. Maria da Conceição Morais Sarmento. Lisboa; I.N.-C.M., 1981,

p.412-422).

[o poder e a organização dos livros, o louvor ambivalente da grandeza] Diogo Barbosa Machado (1682-1772). Bibliotheca Lusitana (1741-1759).

(Prólogo) (1741).

“(...)."

Com mysteriosa disposiçaõ da Providencia esperou a Bibliotheca Lusitana ideada hà mais de hum Seculo pelo laborioso disvelo de varoens eruditos o feliz Reynado de V. Magestade para sahir ao theatro do Mundo.

Verà reduzido a hum Sucinto Mappa a elegante facundia dos Oradores, a suave afluencia dos Poetas, a armonia sem dissonancia dos Musicos, e a explicação das fabulas nos Mythologicos; aos Interpretes Sagrados correndo o veo ao Sanctuario das Escrituras; aos Theologos decifrando os mysterios dos divinos Attributos; aos Jurisconsultos penetrando as dificuldades dos Canones Ecclesiasticos, e das Leys lmperiaes; aos Historiadores referindo os Sucessos das idades passadas; aos Chronologos computando o tempo por Lustros, e Olympiadas, aos Astronomos compassando o movimento dos Ceos, e observando os aspectos dos Planetas; aos Anatomicos examinando a organização dos corpos, e os Medicos descubrindo saudaveis remedios para conservaçaõ da vida."

(Lisboa Occidental: na Oficina de Antonio Isidoro da Fonseca, 1741, t.I, s/p.)

[a biblioteca espaço de língua e de memória]

Memorias de Literatura Portugueza, publicadas pela Academia Real das Sciencias de Lisboa (1792).

Prologo (1792).

“(...).

Saõ por conseguinte a Lingua, e a Historia Portugueza, consideradas em todos os possiveis aspectos, e relações, os dous objectos que constituem, o que a Academia quiz entender por Litteratura Portugueza; objectos naõ só entre si análogos, mas tambem diversos, e separados de toda a outra erudiçaõ, que, ou compete a póvos estranhos, ou pela generalidade dos seus assumptos, pertence a todo o genero humano sem respeito particular a naçaõ alguma."

(Lisboa: Officina da Academia Real das Sciencias, 1792, tomo I, s/p.).

[a biblioteca como factor de bem-estar]

Alvará de D. Maria 1 criando A Real Bibliotheca Pública da Corte (1796).

“(...).

Ordeno que na Minha Corte, e Cidade de Lisboa se erija, e estabeleça logo huma Pública, e bem provida Livraria, que se denominará A Real Bibliotheca Pública da Corte, e na qual haja todas as competentes Officinas, que são indispensaveis em estabelecimentos desta natureza: E quero que o uso especial, e proprio desta Bibliotheca seja o de ser perpetuamente destinada ao bem das Letras, e beneficio contínuo dos Meus Vassallos."

(Lisboa: Biblioteca Nacional, 1969, p.1) 
Segunda conclusão possível: uma Biblioteca é a organização de um conjunto de livros para que assim possam ser fruídos.

\section{Segundo registo - relato de memória. 0 que é urna Biblioteca 3. Um caso. (a Biblioteca J. S. da Silva Dias do C.H.C.)}

Pelo final dos anos 70 do século XX, a Faculdade de Ciências Sociais e Humanas da Universidade Nova de Lisboa viu o seu corpo docente acrescido com a integração de um conjunto de novos nomes e rostos chegados de Coimbra. Coordenava e orientava o grupo, todo ele da área da história da cultura e das ideias, o Prof. Silva Dias.

Com um percurso universitário de qualidade e em constante afirmação, urna obra historiográfica notável na erudição e em algumas novidades e sínteses, o Prof. Silva Dias não tinha já provas a prestar, mas sim um projecto a implementar. Esse projecto era simples: criar um grupo de estudo de história das ideias.

Essa intenção foi imediatamente visível nas práticas pedagógicas assumidas na licenciatura em História (História Cultural e das Mentalidades, Cultura Portuguesa, Teoria da História e, mesmo, História de Portugal, disciplinas estas que versavam matérias dos séculos XVIII e XIX) e nas cadeiras introdutórias de História das Ideias das licenciaturas em Línguas e Literaturas Modernas. No início dos anos 80, tornou-se mais palpável com a criação de um espaço de investigação na dependência do Instituto Nacional de Investigação Científica (I.N.I.C.), o Centro de História da Cultura (C.H.C.).

Nesse Centro existiam várias linhas de investigação, mesmo muito variadas, e em forte articulação com ele a docência de um dos primeiros mestrados a funcionar na F.C.S.H., o de História Cultural e Política, também ele de pendor setecentista e, sobretudo, oitocentista.

Um grupo de docentes e de investigadores apostados no ensino da história das ideias, licenciaturas e um mestrado. Mas para tudo ter uma lógica, um pano de fundo comum, o Prof. Silva Dias criou uma Revista, esta mesma onde se registam estas palavras, e uma Biblioteca.

Descarregaram-se em Lisboa, o termo correcto é "descarregar" porque assim aconteceu, milhares, muitos milhares de fichas bibliográficas, nos seus tradicionais $75 \mathrm{~mm} \times 125 \mathrm{~mm}$, que mais não eram do que a fotocópia integral do ficheiro temático do Instituto de História das Ideias da Universidade de Coimbra. Para estas fichas organizaram-se paredes de gavetas de ficheiros metálicos onde aquelas deviam reganhar uma ordem que, com a operação fotocopiadora e com o transporte, se perdera!

A mesma empresa de transportes que trouxe as fichas até Lisboa carregou, também, umas largas dezenas de volumes de livros de edição da Universidade de Coimbra. A estes livros, amontoadas pelo chão do espaço destinado à Biblioteca, foram-se rapidamente juntando muitos e muitos mais, listas imensas de encomenda que alimentavam a Biblioteca.

Foi necessário escolher, adoptar critérios de classificação, criar secções, arrumar em estantes a partir do chão, pensar em leitores que deles fizessem uso, criar sistemas rudimentares de controlo da leitura domiciliária. Os livros foram arrumados (as fichas nunca!), os leitores (professores, investigadores e alunos do mestrado) usaram-nos e 
tiveram-nos na sua posse todo o tempo de que necessitaram, o hábito de requisitar livros estabeleceu-se.

Deste trabalho biblioteconómico, até por causa da sua formação nesta área, foi encarregue a Prof ${ }^{\mathfrak{a}}$ Zília Osório de Castro. Dele tivemos a sorte de participar e ver, assim, crescer uma Biblioteca das mais apetrechadas e recheadas de preciosidades nas áreas em investigação no Centro de História da Cultura (pela Porbase pode verificar-se que cerca de dois milhares de títulos nela existentes não se repetem em qualquer outra Biblioteca da rede). Os leitores são os que mais beneficiam desta "originalidade".

Terceira conclusão possível: urna Biblioteca é um conjunto de leitores.

\section{Segundo registo - relato de memória-opinião. Mas, afinal, o que é uma Biblioteca? Conclusões. (percursos? construções? ... porque de homenagem não se trata!)}

Comecemos pela conclusão possível: uma Biblioteca é um conjunto de livros organizados e utilizáveis pelos leitores.

Tentemos agora explicar porque é que a Biblioteca J. S. da Silva Dias é uma Biblioteca. Como é que se conseguiu fazer de muitos livros, muitas fichas e ficheiros, um mau espaço de leitura e de trabalho uma Biblioteca? Uma Biblioteca, diga-se, formativa, esclarecedora, cordial e amigável ao utilizador e, sobretudo, peça fundamental da investigação e na construção dos saberes expressos por muitos dos seus leitores.

A explicação não nos é muito difícil de dar. Concerteza que, em muito, ela está no saber, na paciência, na capacidade de criar equipa e de autonomizar deveres funcionais que a Profesora Zília Osório de Castro consegue transmitir aos que com ela desinteressadamente trabalham.

o Centro de História da Cultura possui um conjunto largo e diversificado de livros, livros que estão organizados dando resposta aos seus constantes e fiéis leitores, mercê durante anos dos cuidados da Prof ${ }^{\mathrm{a}}$ Zília Osório de Castro que, afinal, assim construiu uma Biblioteca.

\section{BIBLIOGRAFIA}

Álvarez Márquez, Maria del Carmen - El libro manuscrito en Sevilla (siglo XVI). Sevilla:

Ayuntamiento de Sevilla, 2000.

Bouza Álvarez, Fernando J. - Del escribano a la biblioteca. La civilización escrita europea en la Alta Edad Moderna (siglos XV-XVII). Madrid: Editorial Síntesis, 1992.

Chartier, Roger - El orden de los libros. Lectores, autores, bibliotecas en Europa entre los siglos XIV y XVIII. Barcelona: Editorial Gedisa, 1994. 
Eisenstein, Elizabeth L. - The printing revolution in early modern Europe. Cambridge: University Press, 1993.

Febvre, Lucien; Martin, Henri-Jean - L'apparition du livre. Paris: Éditions Albin Michel, 1971, 2. ${ }^{a}$ ed.

Fernandes, Maria de Lurdes Correia - A biblioteca de Jorge Cardoso (+1669), autor do Agiológio Lusitano. Cultura, erudição e sentimento religioso no Portugal Moderno. Porto: Faculdade de Letras da Universidade do Porto, 2000.

Gouveia, António Camões - "Educação e aprendizagens. Formas de poder na paideia do Portugal Moderno", Ler História. Lisboa: n. 35 , 1998, p. 11-44.

Gravura e conhecimento do mundo. O livro impresso ilustrado nas colecções da BN. Coordenação Joaquim Oliveira Caetano. Lisboa: Biblioteca Nacional, 1998.

Marquilhas, Rita - A faculdade das letras. Leitura e escrita em Portugal no séc. XVII. Lisboa: I.N.-C.M., 2000.

Print and Culture in the Renaissance. Essays on the advent of printing in Europe. Edição de Gerald P. Tyson, Sylvia S. Wagonheim. Newark: University of Delaware Press, 1986.

As utilizações do objecto impresso (séculos XV-XIX). Coordenação de Roger Chartier. Lisboa: Difel, 1998.

\section{AUTOR}

\section{ANTÓNIO CAMÕES GOUVEIA}

\section{FCSH-UNL e CHC}

Licenciado em História e doutorado em História das Ideias, especialização em História das Ideias Sociais, pela F.C.S.H. da U.N.L. Nessa mesma Faculdade dá aulas desde 1981, tendo estado entre 1992 e 1997 na Comissão dos Descobrimentos. Enquanto docente tem leccionado matérias no âmbito da história da cultura e das ideias, predominantemente dos séculos XV a XVIII. A sua área de interesse científico centra-se na História Social c das Sociabilidades quando aflorada nas dimensões da História da Cultura e da História Religiosa. 